\title{
PSYCHE
}

VOL. XLVI

MARCH, 1939

No. 1

\section{A SIMPLE STROBOSCOPIC METHOD FOR THE STUDY OF INSECT FLIGHT}

\author{
By Leigh E. ChadWick \\ Biological Laboratories, Harvard University
}

The methods which have been used for the study of insect wing motion may be reduced for purposes of comparison to six types. Briefly these are (1) the deductive method, (2) the acoustic method, (3) the visual or optical method, (4) the graphic method, (5) the photographic method, and (6) the stroboscopic method. A short discussion of them and of the sort of information they have yielded will be useful in judging the possibilities of the new application of the stroboscopic method outlined below. Further details and references may be found in the works of Prochnow (1924), Weber (1933), Magnan (1934) and Snodgrass (1935).

The deductive method is essentially that of the earlier anatomists. Supplemented by manipulation of dead or anæsthetized specimens it is still useful in studying the more intimate mechanism of the thorax. It cannot be expected to give exact information as to the actual motions of the wings in flight, nor a fortiori as to their rate.

The principle employed in the acoustic method is to match the insect's Flugton with the tone of a tuning fork or other instrument of known frequency. This method was applied extensively by Landois (1867) for rate determinations, but his results have not agreed too well with those obtained more directly with kymograph or camera. The relation between the pitch of an insect's tone and the frequency of its wing motion is still not completely understood, and in many cases 
it appears likely that harmonics may be mistaken for the fundamental. For this reason, and because of difficulties thought to be introduced by the Doppler effect, not much attention has been given to this method by later workers.

The optical method of Wheatstone (1827) was applied by Marey (1868) to the study of wing motion. By gilding areas of the wing he was able to observe its trajectory in living insects held with forceps, and confirmed Pettigrew's (1868) deduction that the wing stroke follows the outline of a figure-8. The type of problem for which this method is suitable is illustrated further by the work of Stellwaag (1916), who was able thus to observe the differential action of the wings in steering. The method cannot be called on, however, for the sort of detail available so abundantly in a photograph, and has the further disadvantage that information gained from it must often pass through a stage of subjective interpretation before it reaches the record. It permits some degree of measurement of the various amplitudes of the wing motion, but affords no data as to rate.

Marey (1868) also introduced the use of the kymograph in the study of wing motion. This instrument gives a permanent non-subjective record, from which it is easy to calculate frequencies, but is limited in other directions. The wing of the insect, used as the recording lever, is of fixed radius, and its motion is complex. If undue friction is to be avoided, only a small fraction of the arc described by the wing tip may be recorded at one time. Insofar as frequency measurements are concerned, the results obtained by Marey and other students who have used the graphic method agree, on the whole, within the limits of normal variation with data derived from other techniques. The distortions bulk larger, however, where it is desired to achieve a true picture of the unhampered motion of the wing. Naturally the kymograph may be used only with fastened and not with freely flying insects.

A third technique introduced by Marey and in the development of which his followers have had a large share is that of high-speed photography. Theoretically this is the most advantageous method for the study of insect flight, but its application is difficult. The high rate at which the wings are moved, 150-250 beats per second being not uncommon 
among the Diptera and Hymenoptera, fixes the length of exposure, and the duration between successive exposures for motion pictures, at exceedingly low limits. To obtain adequate illumination at such frequencies becomes a very real problem, which is intensified by the small size of many species. Added to the photographic difficulties are those of posing the often unwilling specimens. Under these conditions, the method proves expensive in time, film and apparatus,-yet the results which it promises serve amply to justify continued efforts toward its perfection. The extent to which the obstacles mentioned have been overcome at present may be gauged by reference to the fine reproductions in Magnan (1934).

With the more evident merits and disadvantages of these several methods in mind, we may proceed to discuss the stroboscopic technique. The stroboscopic principle has been the basis of most of the attempts at high-speed photography, but Oehmichen (1920) appears to have been the only worker who has previously made much use of the stroboscope for the visual study of insect flight. With the stroboscope, cyclic motions may be made to seem to stand still (and to proceed slowly forward or in reverse) no matter what the actual frequency may be. All that is necessary is an intermittent source of light tuned to synchrony (or near synchrony) with the motion to be observed. In Oehmichen's apparatus light was provided by electric discharge across a spark gap or through a Geissler tube. Frequency could be synchronized automatically with that of the wings by an ingenious arrangement which allowed air currents produced by the wing to open a very light key in the primary circuit at a given phase in each beat. If a variable control of frequency was desired, this key was replaced by a rotary interruptor, the speed of which was regulated by a potentiometer. With this apparatus Oehmichen made visual and photographic observations of much interest, but neither his results nor his method have received much attention since their publication.

The recent development of the Edgerton stroboscope (Germeshausen and Edgerton, 1937) should give a new impetus to studies along this line. Earlier stroboscopes have suffered from shortcomings, either in regard to the source of 
light, which was not dependable, or in regard to control of the frequency, which was unwieldy because of rotational inertia, etc. No difficulties of this sort are met with in the instrument under discussion, in which the flash-frequency of a neon or other low-pressure-filled bulb is controllable instantly by an adjustable electric oscillator. The instrument as supplied operates on $110 \mathrm{~V} \mathrm{60-cycle} \mathrm{AC,} \mathrm{and} \mathrm{gives} \mathrm{direct}$ scale readings in RPM over a range of 600-14,400 cycles per minute (10-240 per second). Values above and below these limits may be calculated easily from harmonic relationships. The accuracy is within $\pm 1.0 \%$ over the full range.

The motion of an insect's wings is fundamentally a cyclic phenomenon, and may therefore be studied by this means. In theory one may place any flying insect before the instrument and by suitable tuning either "stop" the wings completely at any phase in the cycle or permit the cycle to proceed slowly through its several phases while observations are made. How fully these desired conditions may be attained in practise varies considerably with different insects, but, given appropriate treatment of the specimens, the theoretical expectations may be realized very satisfactorily.

Rates may be determined quickly and easily.

Study of the complex motions of the wings is more exacting. Here results depend partly on the operator's patience, since the problem is largely one of inducing the specimens to fly steadily and for longer intervals. Favorable responses can be had in the majority of cases, and are well worth the effort, for the details of the wing motion are displayed with a clarity that is far beyond that of any photographs so far published.

The most evident disadvantage of the method is that, like other visual techniques, it gives no permanent record beyond the notes of the observer. In respect of rate determinations, this objection is less forceful, since one simply tunes to synchrony with the wing frequency, thus obtaining a single standing image, and reads the figures from the dial. Reference to adjacent harmonics quickly settles any doubt as to whether one has been observing the true fundamental or one of its submultiples.

Because of the natural variation in rate, it is often difficult to retain a standing image over any extended period, though 
constant frequency over an interval as long as one minute has been observed not infrequently in Drosophila. In determining rates, this is again of no particular disadvantage in most cases, for here the limits of variation are the significant feature and may be measured quite accurately. Where observations of wing motion as such are to be made, however, it is of importance to know whether or not the apparent motion has the same sign as the true motion. For example, the wings of a noctuid moth during the downstroke show a marked upward curvature of the flexible tips. If the stroboscope be tuned to a frequency slightly above that of the wings, there will be a slow apparent motion in reverse of the true motion, and the wing tip will then seem to be bent upward during the upstroke. Such incongruities may be less patent in the motions of a smaller or more stiff-winged insect, so that caution is necessary. This is particularly so of insects with a very variable rate, whose true frequency may be now to one side and now to the other of the setting on the dial.

Transient motions, for example those involved in starting or in stopping flight, are beyond the scope of such a method. Here, as in many other instances, the ultimate recourse must be the motion-picture camera.

A further weakness of the instruments obtainable at present is that the intensity of the neon bulb is rather low. This means that specimens must be placed close to the source, and outside illumination cut off or reduced to a minimum. In theory it should be quite possible to observe with stroboscopic light the motions of an insect flying freely in a room; practically this ideal is difficult to attain. Even with completely adequate lighting such methods could not be satisfactory with the smaller species. With larger forms, of the size of Leucania unipuncta Haw., for instance, they may be useful, once the essential improvements have been made.

With the cooperation of Professor Edgerton, of the Massachusetts Institute of Technology, the writer has been supplied with additional equipment, including tubes of higher intensity. These give a bluish-white light which is suitable for certain types of photographic work. Photography with the neon tubes is out of the question. Unfortunately the bluish-white light seems to have an inhibitory 
effect upon many insects, so that these tubes have not been as useful in the study of free flight as had been hoped. Whether this is due to some peculiarity of the spectrum, or to an effect of flicker at the higher intensities, which is lacking with the neon bulb, has not been determined. Certain moths are sensitive to noise, and respond adversely to the high-voltage crackle from these tubes as well as to the quality of the light. Still it has been possible to take readings on the wing rate of these and other insects flying freely in a room $12^{\prime} \times 15^{\prime}$, and observations on specimens confined in jars and other containers are often productive. The brighter bulbs have also been used to advantage in studying specimens held in fixed position. At present it is not possible to obtain tubes of this sort which will operate at frequencies much above 100 per second. In connection with the problem of lighting, it may be remarked that, no matter how perfect it may be made, there will always be the natural variation in wing frequency to deal with, as well as the limitation set by what the human eye can observe in a small object traveling rapidly through space.

Where specimens held in fixed position are to be studied, the technique of fastening them is important. A discussion of the problems this introduces would lead beyond the limits of this article, and must be deferred to another occasion.

Finally, one additional limitation of the stroboscopic method should be noted. At rates well below the fusion frequency for the human eye, there is, as might be expected, a disagreeable flicker. This is especially objectionable when one is observing through the binoculars. Fortunately the wing rate of most insects is high enough so that this drawback is of minor consequence. The writer finds observation not uncomfortable at frequencies as low as 20 or 25 per second, where detail, such as motions of parts of the thorax, is to be studied. Direct rate readings are possible down to the limit of 10 per second, or may be taken in higher multiples if this seems preferable.

In concluding this criticism of the stroboscopic method, one may point again to the great advantage of being able to make direct visual observation of the motions of flight, at a rate determined by the observer, and also to the large number of observations that can be made within a limited time. 
It is quite practicable to take a series of rate readings on one individual at 10 -second intervals. With a series of specimens, where one observer has done all the handling and recording, the interval between readings has been about 40 or 50 seconds; if the recording is done by a second person, rates may be read on several specimens within a minute.

It is felt that a great deal can be added to our knowledge of insect flight by the more extended use of this type of stroboscope. Much that is now conjectural in regard to the motions of the wings can be replaced by fact, easily and at relatively small expense. Even after high-speed photography has reached the state of perfection desired, and the day is not yet, the stroboscope will still have its own field of usefulness. There is need for extensive observation of living specimens under experimental conditions where photography may be neither necessary, nor possible. For the photographer himself the stroboscope is a valuable adjunct which permits him to study in advance the rate and type of motion which he is about to attempt to photograph. The various shortcomings and difficulties to which attention has been called above are those which have presented themselves during six months work with this instrument on the problems of insect flight and should serve to indicate the natural limitations of the method.

The application of the stroboscope in the study of wing motion has been simplified by the generous cooperation of Professor H. E. Edgerton of the Massachusetts Institute of Technology. The writer wishes to take this opportunity of acknowledging his assistance and of thanking Professors C. T. Brues and A. C. Redfield, of the Department of Biology, Harvard University, for their encouragement in this work.

\section{List of REFERENCES Cited.}

Germeshausen, K. J. \& Edgerton, H. E. 1937. The Strobotron. Electronics 10 No. 2: 12, Feb. 1937.

Landois, H. 1867. Die Ton- und Stimmapparate der Insekten in anatomisch-physiologischer und akustischer Beziehung. Z. wiss. Zool. 17: 105-184, 187.

Magnan, A. 1934. La locomotion chez les animaux I. Le vol des insectes. Paris, Hermann \& Cie., 1934.

Marey, E.-J. 1868. Déterminations expérimentales du mouvement des ailes des insectes pendant le vol. C. R. Acad. Sci. Paris, 67: 1341. 
Oehmichen, E. 1920. Nos maîtres les oiseaux. Étude sur le vol animal. Paris, Dunod, 1920.

Pettigrew, J. B. 1868. On the mechanical appliances by which flight is attained in the animal kingdom. Trans. Linn. Soc. London, 26: 197.

Prochnow, O. 1924. Mechanik des Insektenfluges. In Schröder, Chr., Handbuch der Entomologie Bd. I, Jena, 1928.

Snodgrass, R. E. 1935. Principles of Insect Morphology. New York, 1935.

Stellwaag, F. 1916. Wie steuern die Insekten während des Fluges? Biol. Zbl. 36: 30 .

Weber, H. 1933. Lehrbuch der Entomologie. Jena, 1933.

Wheatstone, Sir Charles. 1827. Description of the Kaleidophone, etc. Quart. J. Sci. Lit. Art. 1: 21. 

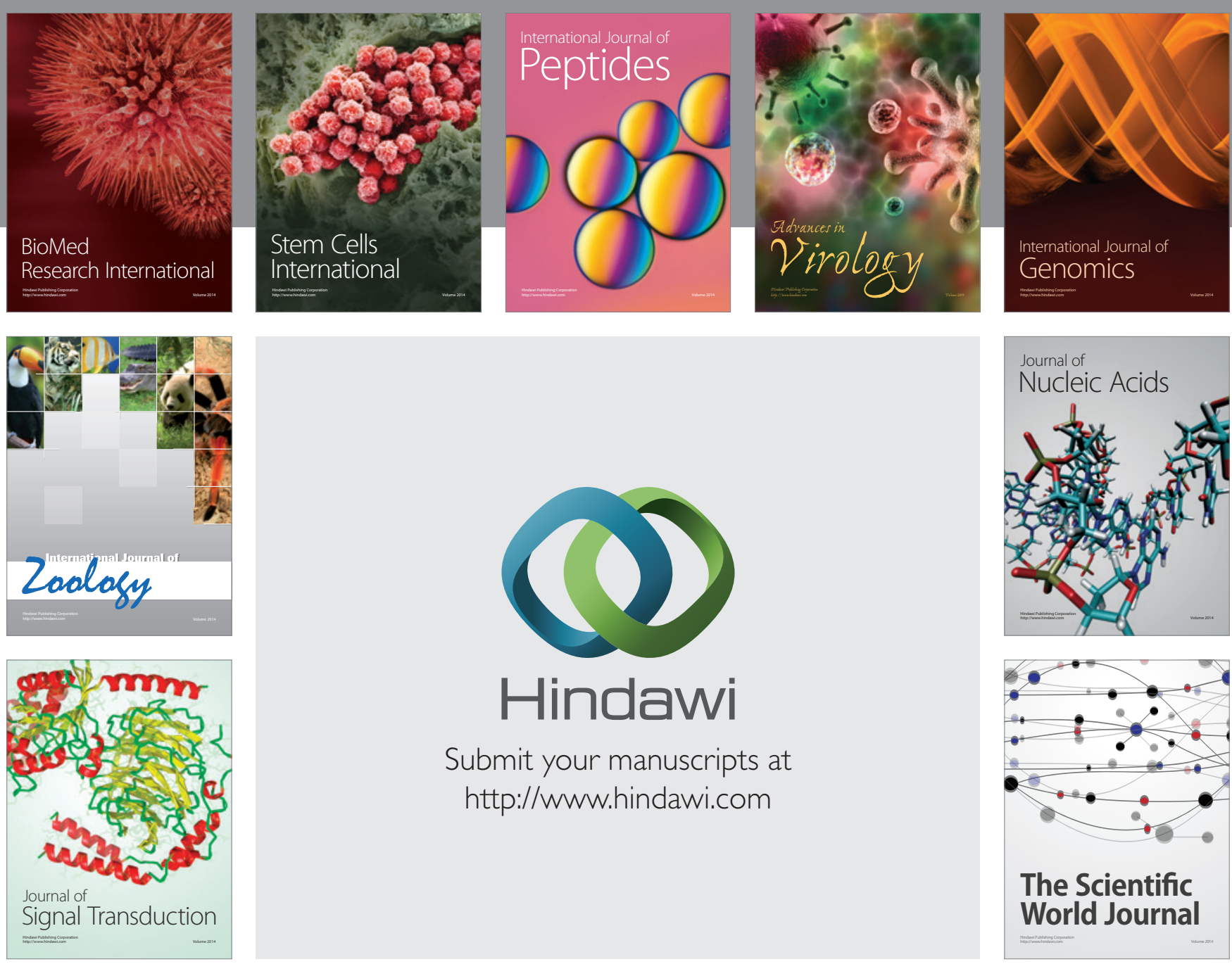

Submit your manuscripts at

http://www.hindawi.com
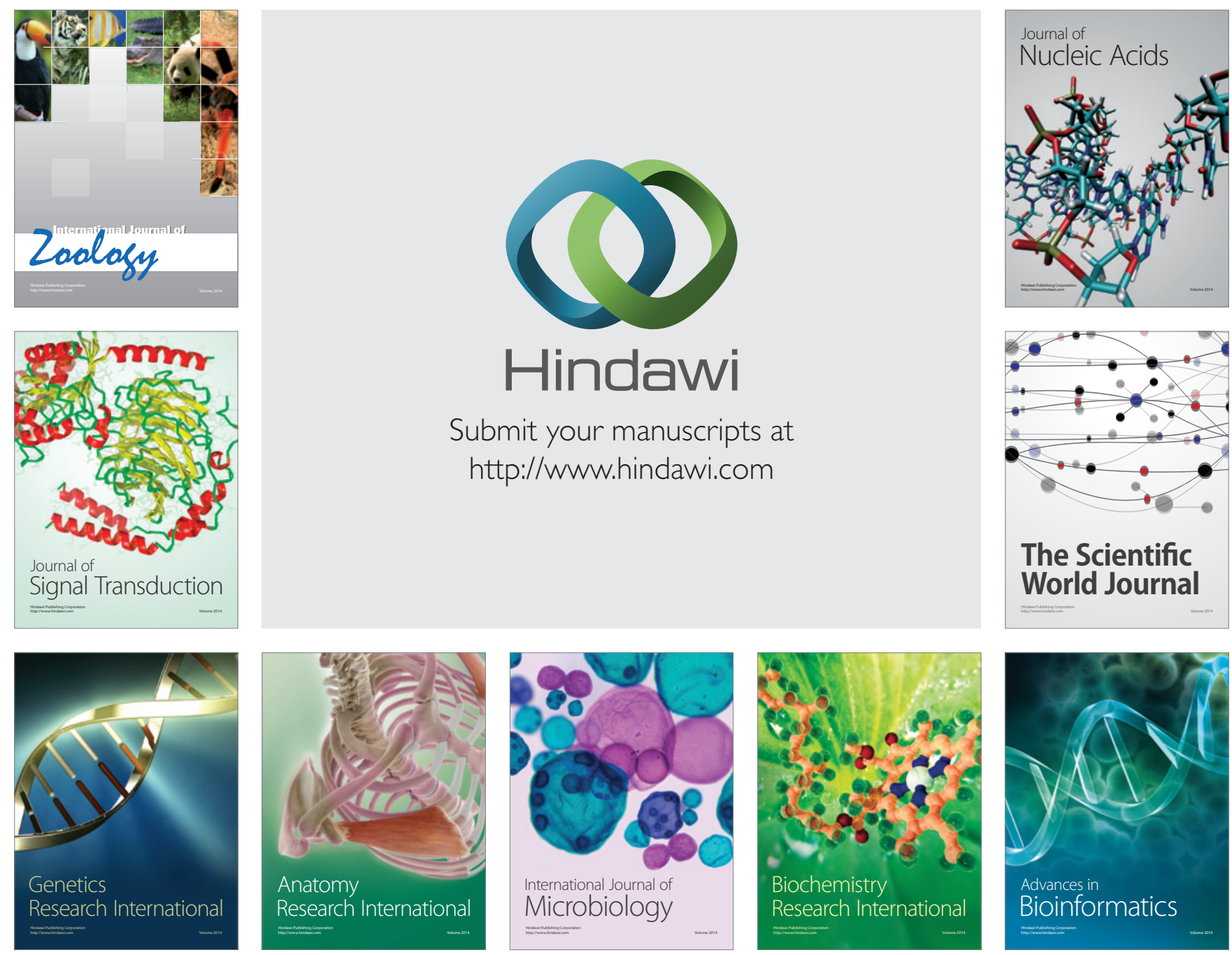

The Scientific World Journal
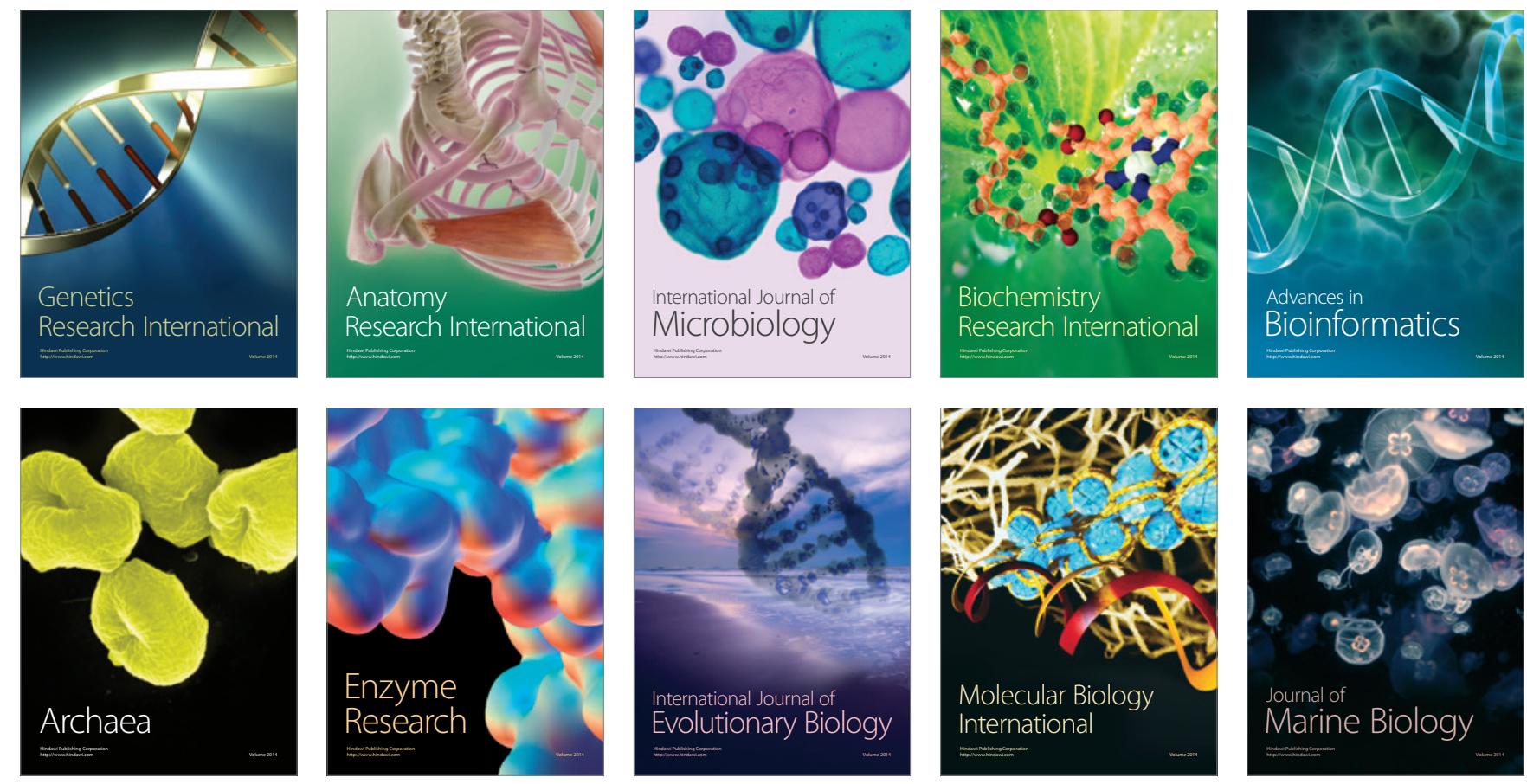